\title{
As redes sociais e a constituição dos sujeitos contemporâneos: um instrumento biopolítico ${ }^{1}$
}

\author{
Nayara Dias Scrimim ${ }^{2}$ \\ Sílvio Gallo ${ }^{3}$
}

\section{Resumo}

Neste artigo procuramos analisar o fenômeno das redes sociais e seu impacto nos processos de subjetivação. 0 campo educativo é nosso pano de fundo e embora não direcionemos nossas análises diretamente para ele, é a partir dele que problematizamos o tema. Após uma contextualização das redes sociais e seu impacto na constituição dos sujeitos, procuramos analisa-las como sendo um dos instrumentos da tecnologia de poder caracterizada por Foucault como biopolítica. Buscamos explicitar como através delas se exerce um "racismo de Estado", que permite estabelecer o corte e a exclusão, para o exercício do controle sobre uma população. É examinada a ação do Facebook no sentido da criação de "comunidades homofílicas" que tem como resultado o apagamento virtual das diferenças e tentamos compreender seus efeitos nos processos de subjetivação. Concluímos chamando a atenção para a possibilidade de resistências e ações do sujeito sobre si mesmo.

Palavras-chave: Mídias sociais; Biopolítica; Processos de subjetivação.

\section{Social medias and contemporary subjects constitution: a biopolitical tool?}

\section{Abstract}

In this paper we aim to analyze, through Foucault's conceptual tools, the contemporary phenomenon of the social medias and its impact to the subjectivation processes. The educational field is our background; our analyzes are not directed to it but it is from it that we problematize the theme. After contextualizing social medias and its impact in the subject's constitution process nowadays, we try to analyze it as one of the tools of the power's technology named biopolitics by Foucault. We try to make explicit that trough them acts the "State's racism" that makes possible stablishing the cut and the exclusion to exercise control over a population. We examine specifically the Facebook's action to create some "homophylic communities" that results in the virtual vanishing of differences and we try to understand its effects on subjectivation processes. We conclude calling attention to the possibility of resistances and actions of the subject over himself.

Keywords: Social medias; Biopolitics; Subjectivation process.

\section{Introdução}

As mídias sociais ${ }^{4}$, tão inseridas na cultura dos grandes centros urbanos, em seus breves

\footnotetext{
${ }^{1}$ Este texto é resultante de uma dissertação de mestrado.

${ }^{2}$ Professora de Filosofia na rede pública estadual de São Paulo; nayarascrimim@hotmail.com

3 Professor Titular da Faculdade de Educação da Universidade Estadual de Campinas e Pesquisador do Conselho Nacional de Desenvolvimento Científico e Tecnológico (CNPq), Piracicaba; gallo@unicamp.br.

${ }^{4}$ Sabemos que há uma discussão conceitual no campo dos estudos da comunicação sobre a diferenciação entre os termos mídias sociais e redes sociais. Para alguns estudiosos da comunicação, as redes sociais são a relação entre ao menos dois elementos: os sujeitos (podendo ser pessoas, instituições ou grupos), e suas conexões (são as interações ou laços sociais). E mídias sociais são os sites e/ou aplicativos na internet construídos para permitir interação social e

Periódico Horizontes - USF - Itatiba, SP - Brasil - e019020
} 
anos de existência, possibilitaram novas formas de ser e estar no mundo, ou seja, novas formas de constituir sujeitos. Basta observar ao nosso redor, seja no ponto de ônibus, no consultório médico, na fila do banco, na padaria, no trânsito e, inclusive, nas salas de aula, as pessoas estão conectadas a estas tecnologias, o que, inegavelmente, impacta o processo educacional, tanto no que se refere à educação formal como à não-formal. Neste artigo, estaremos voltados para a relação entre as mídias sociais e o processo de constituição dos sujeitos contemporâneos em idade escolar, tendo em vista que esses sujeitos já nasceram em uma sociedade em que as redes sociais são uma realidade para grande parte da população ${ }^{5}$.

Para entender como se dá esse processo de subjetivação ${ }^{6}$, é preciso levar em consideração que, no contexto atual, as mídias sociodigitais têm modificado as formas de interação social e que a educação formal ainda segue padrões obsoletos e indiferentes a tais mídias. Assim, faz-se necessário compreender estas transformações e expor o choque que ocorre quando novas tecnologias são inseridas, pelos chamados nativos digitais ${ }^{7}$, em um ambiente educacional ainda resistente a elas. Isso porque, devido ao fato de que ambos ambientes - escola e redes sociais - terem importante influência no processo de subjetivação, compreender o impacto dessas mídias na escola e nos sujeitos em idade escolar pode contribuir com preciosas ferramentas para a transformação de nossos meios de educação, permitindo um melhor uso destas tecnologias que já constituem tais sujeitos ${ }^{8}$.

Há redes sociais para os mais variados tipos de situações e intenções e, todas elas, de certa forma, influenciam na constituição dos sujeitos. Em meio a uma gama de possibilidades, eis alguns exemplos: para se interagir com amigos, Facebook; para bate-papos, WhatsApp e

\footnotetext{
o compartilhamento de informações em vários formatos: fotos, mensagens, ícones entre outros (RECUERO, 2009). Neste artigo não faremos esta distinção dos termos, evitando o uso excessivamente repetido de um mesmo termo.

${ }^{5}$ De acordo com recentes dados divulgados pelo IBGE, das 126,3 milhões de pessoas que utilizaram a Internet em 2017, $95,5 \%$ das pessoas o fizeram para trocar mensagens em suas redes sociais (IBGE, 2018).

${ }^{6}$ Segundo a definição de Revel: "o termo 'subjetivação' designa, para Foucault, um processo pelo qual se obtém a constituição de um sujeito, ou, mais exatamente, de uma subjetividade. Os 'modos de subjetivação' ou 'processos de subjetivação' do ser humano correspondem, na realidade, a dois tipos de análise: de um lado, os modos de objetivação que transformam os seres humanos em sujeitos - o que significa que há somente sujeitos objetivados e que os modos de subjetivação são, nesse sentido, práticas de objetivação; de outro lado, a maneira pela qual a relação consigo, por meio de um certo número de técnicas, permite constituir-se como sujeito de sua própria existência" (REVEL, 2005, p.82).

${ }^{7}$ Termo cunhado por Mark Prensky em seu artigo: "Digital natives, digital immigrants", para se referir aos sujeitos nascidos na era digital.

${ }^{8}$ Para o tema do impacto das tecnologias digitais e redes sociais na educação, sugerimos: PALFREY; GASSER, 2011; VERMELHO; VELHO; BERTONCELLO, 2015; VEEN; VRAKKING, 2009.
} 
Telegram; para ter um network, Linkedin; para flertar, Tinder, Happn, AdoteUmCara, Grindr; para interagir com os vídeos de amigos, Snapchat; para aprender coisas novas, basta ver um tutorial no Youtube. Em todas elas, o que há em comum? Os usuários (cada qual com seu perfil) e suas interações.

A influência dessas novas tecnologias é tamanha que não é possível ignorá-las, pois, por meio dessas interações, tem-se modificado as mais diversas áreas da atividade humana, tais como: as formas de consumo, a sexualidade, a participação política, o acesso à cultura e à educação ${ }^{9}$. Elas atuam diretamente na formação de muitos estudantes, nos dias de hoje, tornando-se muito mais do que algo passageiro, ou restrito a uma época. Daí a necessidade de pensar sua influência na constituição dos sujeitos contemporâneos.

Para tanto, buscamos compreender os sujeitos de nosso tempo através de ferramentas oferecidas por Michel Foucault. Apesar de esse autor ter morrido antes criação e da expansão das redes sociais, ele muito refletiu sobre o processo de subjetivação nas relações de poder. Com essas reflexões, buscou mostrar como se dá de diferentes modos o tornar-se sujeito ao longo da história, em diferentes formas de relações e em diversos aspectos.

Foucault pensa o sujeito como objeto que é constituído por influências exteriores a ele e, também, como sujeito que pensa estas influências e se constrói a si mesmo. De modo que a palavra "sujeito", segundo o próprio Foucault, possui um duplo sentido: "Há dois significados para a palavra sujeito: sujeito a alguém pelo controle e dependência, e preso à sua própria identidade por uma consciência ou autoconhecimento. Ambos sugerem uma forma de poder que subjuga e torna sujeito a" (FOUCAULT, 1995, p.235).

Seguindo a trilha aberta por ele, analisamos como as redes sociais digitais afetam o processo de subjetivação dos sujeitos de nosso tempo, tanto como algo que produz o assujeitamento pelo "controle e dependência" quanto como algo que permite ao usuário destas redes se construir a si mesmo.

As redes sociais, por serem produto do nosso presente e estarem em constante

\footnotetext{
${ }^{9}$ Para Paulo Freire, esse processo educacional se dá por meio de relações, sendo mediatizado pelo mundo. A partir desta concepção, podemos entender que as redes sociais constituem mais um desses aparatos que mediatizam a educação desses sujeitos. "Ninguém educa ninguém, ninguém educa a si mesmo, os homens se educam entre si, mediatizados pelo mundo" (FREIRE, 2005. p.39).
}

Periódico Horizontes - USF - Itatiba, SP - Brasil - e019020 
movimento, não podem ser observadas como algo pronto e finalizado, pois, assim como um caleidoscópio, apresentam múltiplas faces que estão em constante devir. É necessário, portanto, compreender de forma flexível algumas dessas possibilidades de investigação. Sendo assim, entenderemos melhor estes mosaicos sob a perspectiva dos estudos de Foucault, cuja dificuldade esse filósofo expressa em O Belo Perigo:

Em primeiro lugar, o fato de que, para mim, é sempre muito difícil falar do presente. Claro, acho que eu até poderia falar das coisas que ainda estão muito próximas de nós, mas sob a condição de que houvesse entre essas coisas bem próximas e o momento em que escrevo essa ínfima defasagem, essa fina película através da qual a morte se instaurou (FOUCAULT, 2016, p.47).

Estamos, pois, cientes das dificuldades de analisar um tema no qual estamos imersos, sobretudo a quase impossibilidade de tomar distância, de poder separar aquilo que somos e vivemos daquilo que estudamos. Mas, ainda assim, correremos os riscos inerentes, para ao menos começar a construir uma perspectiva crítico-analítica destes fenômenos e seus impactos nos processos de subjetivação, em especial aqueles que se desenrolam no campo educativo. Dados os limites deste artigo, restringiremos nossa análise às redes sociais no contexto daquilo que o filósofo denominou biopoder, como explicitaremos adiante, embora o referencial foucaultiano possibilite analíticas mais abrangentes.

\section{As redes sociais como instrumento do biopoder}

Ao estudar os processos de subjetivação, isto é, a história dos modos de constituição do sujeito ao longo do tempo, Foucault nos mostra que houve uma transição entre o poder soberano, baseado nos suplícios, para o poder disciplinar, que por meio de instituições como os colégios e quartéis, penetraram na vida cotidiana dos sujeitos, realizando um controle detalhado, minucioso de seus gestos, atitudes, comportamentos, hábitos e discursos. Uma vez controlados os corpos individuais, Foucault fala sobre uma nova forma de poder, agora exercido sobre o conjunto dos viventes constituídos em uma massa por meio de certos discursos e ações. Tratase daquilo que ele denominou biopoder. Em suas palavras: 
Mais precisamente, eu diria isto: a disciplina tenta reger a multiplicidade dos homens na medida em que essa multiplicidade pode e deve redundar em corpos individuais que devem ser vigiados, treinados, utilizados, eventualmente punidos. E, depois, a nova tecnologia que se instala se dirige à multiplicidade dos homens, não na medida em que eles se resumem em corpos, mas na medida em que ela forma, ao contrário, uma massa global, afetada por processos de conjunto que são próprios da vida, que são processos como o nascimento, a morte, a produção, a doença, etc. (FOUCAULT, 1999, p.289).

Vemos as redes sociais agindo não somente disciplinando os sujeitos em sua individualidade como também atuando como uma forma de poder sobre a população. ${ }^{10}$ Segundo Foucault, essas duas formas de poder não são excludentes, o biopoder é:

uma tecnologia de poder que não exclui a primeira, que não exclui a técnica disciplinar, mas que a embute, a integra, que a modifica parcialmente e que, sobretudo, vai utilizá-la implantando-se de certo modo nela, e incrustando-se efetivamente graças a essa técnica disciplinar prévia (FOUCAULT, 1999, p.288289).

Essa nova forma de governar, a biopolítica, caracteriza-se por regulamentar a população através de um poder exercido sobre todos os aspectos da vida humana, governam-se as pessoas, não mais em sua individualidade pelas técnicas disciplinares, mas, de forma ainda mais imperceptível, pela sedução dos sujeitos por meio de mecanismos que agem diretamente na vida em sociedade. Tal tecnologia penetra em todos os momentos da vida, como mecanismos de bem-estar social:

As disciplinas lidavam praticamente com o indivíduo e com seu corpo. Não é exatamente com a sociedade que se lida nessa nova tecnologia de poder [...]; não é tampouco com o indivíduo-corpo. É um novo corpo: corpo múltiplo, corpo com inúmeras cabeças, se não infinito pelo menos necessariamente numerável. É a noção de 'população'. A biopolítica lida com a população, e a população como problema político, como problema a um só tempo científico e político, como problema biológico e como problema de poder [...] (FOUCAULT, 1999, p.292-293).

\footnotetext{
10 Para uma análise das redes sociais no contexto do poder disciplinar, sugerimos a leitura de SCRIMIM (2019); SCRIMIM; FRANÇA (2014).
}

Periódico Horizontes - USF - Itatiba, SP - Brasil - e019020 
Sob o véu desta nova forma de governar, conduz-se toda uma população como sujeitos que participam ativamente da produção da vida coletiva. Podemos observar que as redes sociais atuam também sob esta lógica, pois elas são, democraticamente, uma tecnologia de vigilância, que conduz as populações a tomar decisões individuais e coletivas por meio de uma submissão voluntária e desejada.

Ao contrário do que era o poder soberano, que se pautava no "deixar viver e fazer morrer", pois o rei detinha a escolha sobre quem poderia viver e quem deveria morrer, agora, o que se tem na lógica da biopolítica é o "fazer viver e deixar morrer", pois se trata de poder interferir no modo como as pessoas irão viver.

\begin{abstract}
Aquém, portanto, do grande poder absoluto, dramático, sombrio que era o poder da soberania, e que consistia em poder fazer morrer, eis que aparece agora, com essa tecnologia do biopoder, com essa tecnologia do poder sobre a 'população' enquanto tal, sobre o homem enquanto ser vivo, um poder continuo, cientifico, que é o poder de 'fazer viver'. A soberania fazia morrer e deixava viver. $\mathrm{E}$ eis que agora aparece um poder que eu chamaria de regulamentação e que consiste, ao contrário, em fazer viver e em deixar morrer (FOUCAULT, 1999, p.294).
\end{abstract}

Nesse sentido, defendemos a ideia que as redes sociais são um tipo de instrumento de biopoder, pois constituem sujeitos tanto em sua individualidade, quanto na coletividade, a fim de conduzir o modo pelo qual suas vidas serão governadas pelo próprio Estado. Do modo como assistimos, ao longo desses últimos anos, as redes sociais vêm sendo utilizadas como ferramentas para militância política, para eleger governantes e, até mesmo, para modificar a maneira pela qual alguns estadistas discursam. A exemplo disto temos Trump e Bolsonaro ${ }^{11}$, que são aplaudidos por seus seguidores por aparentarem ser pessoas disponíveis ao diálogo nas redes sociais. Ou seja, cada vez mais somos governados (e governamos os outros) através das mídias de relacionamento.

Mas, se o que caracteriza a biopolítica é o exercício de um controle direto sobre a vida das populações e das pessoas que as constituem, se o Estado que opera segundo essa tecnologia

11 Consultar: BRANT, D. https://www1.folha.uol.com.br/poder/2018/11/bolsonaro-segue-passos-de-trump-eadota-rede-social-para-discursar.shtml

Periódico Horizontes - USF - Itatiba, SP - Brasil - e019020 
de poder tem por princípio básico a manutenção da vida, uma questão se impõe: como pode o Estado exercer o "direito de matar"?

A resposta de Foucault é incisiva: através do racismo. Vejamos sua caracterização do fenômeno:

Com efeito, o que é o racismo? É, primeiro, o meio de introduzir afinal, nesse domínio da vida de que o poder se incumbiu, um corte: o corte entre o que deve viver e o que deve morrer. No contínuo biológico da espécie humana, o aparecimento das raças, a qualificação de certas raças como boas e de outras, ao contrário, como inferiores, tudo isso vai ser uma maneira de fragmentar esse campo do biológico de que o poder se incumbiu; uma maneira de defasar, no interior da população, uns grupos em relação aos outros. Em resumo, de estabelecer uma cesura que será do tipo biológico no interior de um domínio considerado como sendo precisamente um domínio biológico. Isso vai permitir ao poder tratar uma população como uma mistura de raças ou, mais exatamente, tratar a espécie, subdividir a espécie de que ele se incumbiu em subgrupos que serão, precisamente, raças. Essa é a primeira função do racismo: fragmentar, fazer cesuras no interior desse contínuo biológico a que se dirige o biopoder (FOUCAULT, 1999, p.304-305).

Assim, podemos entender o racismo como esse poder de corte, de promover uma fragmentação de um contínuo biológico que pode, então, ser separado, organizado, controlado e normatizado, se necessário com a exclusão daqueles que desviam excessivamente, que escapam à norma e que já não podem ser normalizados, posto que tal exclusão fica justificada pela proteção e a garantia de direitos para aqueles que estão na norma. No âmbito deste nosso estudo, isso se evidencia. As redes sociais estão se constituindo, cada vez mais, no instrumento do exercício deste corte, de modo a cuidar de uma população que, mesmo heterogênea, passa por fortes processos de homogeneização.

Foucault é bastante claro: este racismo que opera na biopolítica é um "racismo de Estado". Aqui já não é o preconceito de um indivíduo contra outro indivíduo o que importa, mas sim a ação legítima do Estado de tirar a vida de alguns para proteger e garantir a vida de toda uma população. Foi a este tipo de "espetáculo" que assistimos com o governo nazista na Alemanha, com o governo estalinista na União Soviética. É também a este tipo de espetáculo que assistimos quando presenciamos extermínios em periferias brasileiras, não raro aplaudidos pela população. 
A especificidade do racismo moderno, o que faz sua especificidade, não está ligado a mentalidades, a ideologias, a mentiras do poder. Está ligado à técnica do poder, à tecnologia do poder. Está ligado a isso que nos coloca, longe da guerra das raças e dessa inteligibilidade da história, num mecanismo que permite ao biopoder exercer-se. Portanto, o racismo é ligado ao funcionamento de um Estado que é obrigado a utilizar a raça, a eliminação das raças e a purificação da raça para exercer seu poder soberano (FOUCAULT, 1999, p.309).

Se nos regimes totalitários do século XX a propaganda foi um dos elementos centrais da tecnologia de poder biopolítico para o exercício do racismo como instrumento de corte, separação e governo, nos Estados democráticos do século XXI as redes sociais parecem servir muito bem a este propósito. Num panorama muito distinto daqueles regimes, é verdade, posto que hoje vivemos "tempos democráticos" nos quais o extermínio de populações não seria bem visto, mas o tipo de jogo político que se leva a cabo com a participação feliz e efetiva de grandes parcelas da população serve aos mesmos propósitos de estabelecer cortes, exclusões e governo.

No campo da educação, alguns exemplos são gritantes. O movimento Escola Sem Partido se utiliza destas mídias como forma de instituir seus discursos sobre o que é bom para toda a educação da sociedade brasileira ${ }^{12}$. Ganhando espaço não só nestas mídias, mas também nas Assembleias Legislativas, nas esferas federal, estadual e municipal de todo o país, de modo especial no período de 2016 a 2018. O que esse movimento faz com a escola e a diversidade de ideias é justamente o que está no seio do biopoder: "fazer viver" os ideais que interessam e "deixar morrer" as discussões contrárias de seus idealizadores, tais como: direitos humanos, feminismo, racismo, LGBTfobia, desigualdade social etc.

Enquanto ferramenta de gestão da vida humana, a biopolítica estabelece, pois, uma forma de controle social, ou seja, cumpre o papel de inclusão e de exclusão dos sujeitos no meio social. Sendo assim, a biopolítica cria armas que, ao mesmo tempo em que regulamentam a vida, fazem eclodir as diferenças e, com isso, deixam morrer o que é preciso que morra para garantir uma certa homogeneidade social. Foucault exemplifica, por meio do racismo de Estado, que as minorias (os indesejados/degenerados) fragmentam o tecido social de modo que se faz necessário estabelecer uma espécie de "limpeza social": "a morte do outro, a morte da raça ruim,

\footnotetext{
12 Não é nosso objetivo aqui fazer uma análise do movimento Escola Sem Partido; o trazemos apenas como um exemplo daquilo que marca o nosso tempo no Brasil, como instrumento do controle biopolítico no campo educativo.
}

Periódico Horizontes - USF - Itatiba, SP - Brasil - e019020 
da raça inferior (ou do degenerado, ou do anormal), é o que vai deixar a vida em geral mais sadia, e mais pura" (FOUCAULT, 1999, p.305).

No caso do movimento Escola Sem Partido, este se tornou vitorioso mesmo não tendo ainda entrado em vigor, pois obteve grande sucesso ao saber como vender seus ideais por meio das redes sociais, ao tornar as ideologias contrárias àquelas que defendem seus idealizadores no grande problema que enfrentamos na sociedade brasileira, e, com isso, enuvia os reais problemas da educação brasileira e os tipos de discussões e conhecimentos que podem ou não ocorrer nas escolas.

\section{Dividir para conquistar}

As redes sociais, na verdade, não criaram novos comportamentos, mas amplificaram comportamentos que já existiam antes delas: no caso das divergências de opiniões, por exemplo, vivenciamos uma guerra na qual cada ponto de vista tornou-se a "verdade absoluta" e aqueles que possuem posicionamento contrário ganharam a condição de inimigos, pois desconstroem a verdade pessoal de cada indivíduo e, assim, devem ser convertidos ou "bloqueados", deixando de ter acesso às postagens uns dos outros.

Deste modo, religiões, partidos políticos, escolas de pensamento, tribos, nações, cores de pele, modos de se vestir, gostos musicais, tudo virou motivo para conflito e fragmentação. 0 biopoder se constitui e também se alimenta por esta divisão; senão, como seria possível fazer a "higienização social" sem que houvesse reações contrárias? É preciso colocar as pessoas umas contra as outras, como assim elucida Guilherme Castelo Branco em Racismo, individualismo, biopoder:

Trata-se da justificativa da manutenção da vida de alguns pela deliberada eliminação de outro qualquer. Frases como "se queres viver, o outro deve morrer" convertem-se num slogan político e são, a todo o momento, utilizadas nas chantagens a respeito do direito à riqueza e ao bem-estar social. Dessa maneira, percebemos que a grande chantagem está numa associação entre eliminação do outro como purificação da sociedade (CASTELO BRANCO, 2009, p.32).

Periódico Horizontes - USF - Itatiba, SP - Brasil - e019020 
É próprio da tecnologia do biopoder se fortalecer controlando as populações, ao "fazer viver" aqueles que melhor se adaptam ao perfil de produção necessitado pelo Estado capitalista e, ao contrário, "deixa morrer" os que não servem para promover o trabalho produtivo, o desenvolvimento econômico e a modernização. Isso porque, pessoas que questionam o status quo, não aceitando menos do que lhes são garantidos por direitos, colocam estes poderes em xeque. Melhor então, que dentro dessa outra instituição de biopoder que é a escola, por exemplo, não se discuta sobre as revoluções, greves e direitos políticos.

A estratégia de fragmentar a sociedade fomentando por meio das redes sociais um debate enviesado e desonesto é uma maneira de nos manter mais conectados, pois ficamos sedentos pelas chamadas tretas, tentando converter o outro em nós mesmos. Assim, ao ficar conectados, consequentemente estamos sendo conduzidos por meio dos algoritmos a ter mais acesso a um tipo de debate que de outro, nos fazendo querer eliminar o outro e sua incômoda forma de pensar (isso ocorre tanto no plano virtual quanto no âmbito do real13). Desse modo, somos nós os próprios executores da higienização proposta pelo biopoder. A tática de fragmentar-nos conquista e fortalece os interesses dos poderes dominantes, que se consolida através de nossos próprios atos.

Diante das críticas sobre essa nova forma de se comportar das pessoas, os desenvolvedores destas redes resolveram aperfeiçoar seus algoritmos a fim de mostrar às pessoas aquilo que mais as agrada. Isso fica evidente nos pronunciamentos do fundador e CEO do Facebook, Mark Zuckerberg, como veremos em seguida.

\section{Apagar as diferenças para melhor conviver}

As redes sociais vão muito além de uma simples forma de entretenimento interativo. São, também, uma forma de gerar comportamentos e disseminar novas formas de pensar, atuando sobre os sujeitos e populações. E isso é de conhecimento de seus desenvolvedores, segundo David Kirkpatrick, em seu livro O Efeito Facebook - os bastidores da história da empresa que

\footnotetext{
${ }^{13}$ Um exemplo foi o assassinato, tão brutal quanto estúpido, de Mestre Moa do Catendê em 2018, quando o debate político tornou-se "motivo" para a eliminação daquele que pensa diferentemente. Ver, por exemplo: https://veja.abril.com.br/blog/bahia/inquerito-conclui-que-morte-de-capoeirista-na-ba-teve-motivacao-politica/.
}

Periódico Horizontes - USF - Itatiba, SP - Brasil - e019020 
conecta o mundo: desde sua origem os criadores da rede social mais utilizada no mundo perceberam o potencial político do invento:

\begin{abstract}
Embora o Facebook não tenha sido concebido como um instrumento político, logo no início seus criadores perceberam que havia ali um potencial peculiar. Durante as primeiras semanas depois de sua criação na Universidade de Harvard, em 2004, os estudantes começaram a divulgar suas opiniões políticas ao substituir sua foto por um bloco de texto que incluía alguma declaração política. 'Naquela época, as pessoas usavam o Facebook para protestar contra o que quer que achassem importante', diz Dustin Moskovitz, cofundador do Facebook. 'Mesmo que estivessem apenas aborrecidas com um problema insignificante na faculdade'. Desde o início as pessoas perceberam intuitivamente que, se aquilo pretendia thes oferecer uma forma de expressar on-line sua verdadeira identidade, então suas opiniões e paixões sobre as questões do momento eram um elemento dessa identidade (KIRKPATRICK, 2011, p.12).
\end{abstract}

Diante disso, os desenvolvedores dessas mídias têm sido acusados de interferência nos processos eleitorais em países como EUA, Brasil, Finlândia etc. A fim de se proteger de tais acusações, Mark Zuckerberg divulgou uma carta em fevereiro de 2017, na qual explicita sua meta de promover a otimização das redes sociais que comanda, buscando findar com as divergências, unindo todos os usuários em uma espécie de comunidade global, para assim vivermos em um mundo melhor. Suas palavras são incisivas:

Para nossa comunidade,

(...) $O$ progresso agora requer que a humanidade se una não apenas como cidades ou nações, mas também como uma comunidade global. Isto é especialmente importante agora. O Facebook luta para nos aproximar e construir uma comunidade global (ZUCKERBERG, 2017, tradução nossa) ${ }^{14}$.

Trata-se de uma sedutora proposta: deixar de lado as diferenças e unir a todos em prol de uma sociedade mundial, capaz de promover a paz, reduzir a pobreza, incentivar pesquisas científicas. Segundo a carta de Zuckerberg, a empresa que ele comanda desenvolverá, por meio do Facebook, uma infraestrutura social a fim de que as pessoas possam construir uma comunidade global que funcione para todos. Impossível não lembrarmos da utopia hippie de

\footnotetext{
${ }^{14}$ To our community, (...) Progress now requires humanity coming together not just as cities or nations, but also as a global community. This is especially important right now. Facebook stands for bringing us closer together and building a global community.
}

Periódico Horizontes - USF - Itatiba, SP - Brasil - e019020 
Lennon nos anos 1970: "imagine todas as pessoas vivendo a vida em paz, [...] numa irmandade de humanos"15. Seria essa mídia social a ferramenta para a realização deste sonho?

Ao falar sobre do que se trata o Facebook, Zuckerberg afirma que não é apenas tecnologia ou mídia, mas uma comunidade de pessoas e, para governar toda essa comunidade, segundo ele, é preciso estabelecer valores e padrões que estejam em comum acordo com todos os usuários, de diversas culturas, países e posicionamentos. Para ele, a melhor forma de fazer isso é por meio do uso da Inteligência Artificial, fazer com que cada pessoa esteja exposta àquilo que mais se aproxime de seu ponto de vista ideológico. Vejamos:

Os princípios orientadores são que os Padrões da Comunidade devem refletir as normas culturais de nossa comunidade, que cada pessoa deve ver o mínimo de conteúdo censurável possível, e cada pessoa deve ser capaz de compartilhar o que quiser, sendo informada de que não pode compartilhar algo tão pouco quanto possível. A abordagem é combinar a criação de um processo democrático em larga escala para determinar padrões com Inteligência Artificial para ajudar a aplicá-los. (ZUCKERBERG, 2017, tradução nossa) ${ }^{16}$.

Essa forma de governança da comunidade, mais uma vez nos remete ao biopoder: controlar toda uma população por meio do oferecimento de um bem estar social, no caso, tornando as pessoas cada vez mais expostas a interações "umbiguistas" através da supervalorização da própria visão de mundo do usuário e reduzindo o acesso a notícias por meio do filtro-bolha do Feed de notícias ${ }^{17}$. Kirkpatrick narra uma situação reveladora: quando foi criada a ideia do Feed, Zuckerberg afirmou: "a morte de um esquilo, na frente de sua casa, pode ser mais importante para você do que pessoas morrendo na África" (KIRKPATRICK, 2011, p.166), confirmando, assim, a imagem de que cada usuário viveria dentro de uma espécie de "bolha", cujos horizontes são definidos por suas preferências sociais. Não nos debruçaremos na perspectiva alienante desta prática, mas reafirmamos que essa rede social promove uma forma

\footnotetext{
${ }^{15}$ Imagine all the people living life for peace, [...] a brotherhood of man.

${ }^{16}$ The guiding principles are that the Community Standards should reflect the cultural norms of our community, that each person should see as little objectionable content as possible, and each person should be able to share what they want while being told they cannot share something as little as possible. The approach is to combine creating a large-scale democratic process to determine standards with Al to help enforce them.

${ }^{17}$ Para que as pessoas não sejam expostas a uma quantidade gigantesca de informações, esta tecnologia pelo perfil e interações do usuário seleciona com o que ele terá contato ou não, priorizando notícias locais e pessoas mais próximas, como familiares.
}

Periódico Horizontes - USF - Itatiba, SP - Brasil - e019020 
de biopoder, na medida em que pratica uma espécie de racismo, através da exclusão do outro. Pode ser apenas a exclusão da vista do usuário, mas esse ato produz uma falsa ideia de comunidade, pois não há diversidade, apaga-se o múltiplo, uma vez que cada usuário só se relaciona com outros que possuem o mesmo perfil de pensamento. Que "irmandade", no sentido da canção de Lennon, seria essa? Uma comunidade do mesmo?

Com essas ferramentas, estamos fabricando sujeitos que, dentro desta lógica, não suportam visões divergentes das suas. Daí, mais uma vez o fortalecimento de projetos como o Escola Sem Partido, como vimos antes, que têm como princípio não expor jovens a opiniões contrárias daquelas de seus familiares, dos adultos por eles responsáveis. Produzir uma comunidade "homofílica" (amizade/amor pelos iguais), ou seja, pessoas que gostam de interagir apenas com aqueles que possuem valores e comportamentos similares aos seus, é algo danoso para a sociedade como um todo, pois, as diferenças continuarão existindo no mundo real, apesar das pessoas não estarem mais em contato com elas no mundo virtual. Entende-se que, na verdade, deveríamos aprender a dialogar, de forma saudável, com aqueles que possuem opiniões diferentes das nossas. Em sua carta de metas anuais de 2018, mais uma vez Zuckerberg reforçou seu intuito:

O mundo está ansioso e dividido, e o Facebook tem muito trabalho a fazer, seja protegendo nossa comunidade de abusos e ódio, se defendendo contra a interferência de governos, ou se assegurando de que o tempo gasto no Facebook seja bem gasto. Meu desafio pessoal para 2018, portanto, é "corrigir esses problemas importantes". (ZUCKERBERG, 2018, tradução nossa) $)^{18}$.

Desse modo, vemos toda uma população de mais de 2 bilhões de usuários do Facebook obedecendo voluntariamente a essa forma de controle e, ainda mais, participando ativamente dela. Isso ocorre porque, por mais que sejam os protagonistas desta ação de estar online, o poder ainda assim atua, continuamente, nas mais diversas reconfigurações (cada vez mais de forma atraente e desejável). Para Foucault o poder é uma relação entre forças, que não age apenas reprimindo e cerceando, mas otimizando e conduzindo. Nas suas palavras, "onde há poder, ele

\footnotetext{
${ }^{18}$ The world feels anxious and divided, and Facebook has a lot of work to do -- whether it's protecting our community from abuse and hate, defending against interference by nation states, or making sure that time spent on Facebook is time well spent. My personal challenge for 2018 is to focus on fixing these important issues.
}

$$
\text { Periódico Horizontes - USF - Itatiba, SP - Brasil - e019020 }
$$


se exerce" (FOUCAULT, 1979, p.138); e aí estamos nós, sujeitos contemporâneos, ao mesmo tempo alvos do controle e agentes de poder nas redes sociais.

\section{Considerações finais}

Ao analisar a influência das redes sociais na constituição dos sujeitos, percebemos que elas agem de modo a docilizar e regulamentar a vida tanto no plano individual quanto coletivo. São ferramentas de constituição das subjetividades contemporâneas e com uma dimensão política importantíssima, visto que, nas novas gerações, raros são os sujeitos que não se constituem na relação direta e intensa com essas ferramentas de comunicação. Ao introduzir a perspectiva biopolítica, Foucault introduziu também a noção de governamentalidade, enfatizando seus dois polos; o governo dos outros e o governo de si mesmo.

Essa noção aparece pela primeira vez na aula de 10 de fevereiro de 1978 , quarta aula do curso Segurança, Território, População. Segundo Castro, "Foucault utiliza o termo 'governamentalidade' para referir-se ao objeto de estudo das maneiras de governar" (2009, p.190). Acompanhemos sua emergência no pensamento do filósofo, quando ele a caracteriza em seus três aspectos:

Por esta palavra, 'governamentalidade', entendo o conjunto constituído pelas instituições, os procedimentos, análises e reflexões, os cálculos e as táticas que permitem exercer essa forma bem específica, embora muito complexa, de poder que tem por alvo principal a população, por principal forma de saber a economia política e por instrumento técnico essencial os dispositivos de segurança. Em segundo lugar, por 'governamentalidade' entendo a tendência, a linha de força que, em todo o Ocidente, não parou de conduzir, e desde há muito, para a preeminência deste tipo de poder que podemos chamar de 'governo' sobre todos os outros - soberania, disciplina - e que trouxe, por um lado, o desenvolvimento de toda uma série de aparelhos específicos de governo [e, por outro lado], o desenvolvimento de toda uma série de saberes. Enfim, por 'governamentalidade', creio que se deveria entender o processo, ou antes, o resultado do processo pelo qual o Estado de justiça da Idade Média, que nos séculos XV e XVI se tornou o Estado administrativo, viu-se pouco a pouco 'governamentalizado' (FOUCAULT, 2008, p.143-144).

A ideia de governamentalidade tornou-se chave no pensamento de Foucault porque

Periódico Horizontes - USF - Itatiba, SP - Brasil - e019020 
explicita de forma direta o governo das condutas, implicando também na emergência de contracondutas, pois, segundo a ótica do filósofo, "lá onde há poder há resistência e, no entanto (ou melhor, por isso mesmo) esta nunca se encontra em posição de exterioridade em relação ao poder" (FOUCAULT, 1985, p.91). A governamentalidade articula governo e subjetivação, posto que na mesma medida em que somos governados, governamos a nós mesmos. Em outras palavras: é no mesmo movimento em que somos sujeitados ao poder que temos o poder de agir sobre nós mesmos. As redes sociais exercem importante papel na contemporaneidade porque, conforme procuramos evidenciar ao longo deste artigo, elas nos abrem justamente esta dupla atuação e nos subjetivamos nelas, na mesma medida em que somos por elas subjetivados.

Mas, se onde há poder há resistência, se a condução de condutas implica na emergência de contracondutas, as redes sociais são também espaço de resistências, oportunidade de contracondutas $^{19}$. Não temos condições de desenvolver aqui este tema, mas não poderíamos encerrar este artigo sem ao menos enunciar as linhas de fuga das transgressões que se produzem no campo das mídias sociais.

\section{Referências}

CASTELO BRANCO, G. Racismo, individualismo, biopoder. Aurora, Curitiba, v.21, n.28, p.29- 38, jan-jun 2009.

CASTRO, E. Vocabulário de Foucault. Belo Horizonte: Autêntica, 2009.

FOUCAULT, M. Microfísica do poder. Rio de Janeiro: Graal, 1979.

FOUCAULT, M. História da sexualidade 1 - a vontade de saber. 6. ed. Rio de Janeiro: Graal, 1985.

FOUCAULT, M. O sujeito e o poder. In: RABINOW, P.; DREYFUS, H. Michel Foucault: uma trajetória filosófica: para além do estruturalismo e da hermenêutica. Rio de Janeiro: Forense Universitária, 1995 p.231-249.

FOUCAULT, M. Em defesa da sociedade. São Paulo: Martins Fontes, 1999.

\footnotetext{
${ }^{19}$ A esse respeito, ver, por exemplo: GALLO, 2017 e GALLO; ASPIS, 2011.

Periódico Horizontes - USF - Itatiba, SP - Brasil - e019020
} 
FOUCAULT, M. Segurança, Território, População. São Paulo: Martins Fontes, 2008.

FOUCAULT, M. O belo perigo. Trad. Fernando Scheibe, Belo Horizonte: Autêntica, 2016.

FREIRE, P. Pedagogia do oprimido. 42. ed. Rio de Janeiro: Paz e Terra, 2005.

GALLO, S. Biopolítica e subjetividade: resistência? Educar em Revista, Curitiba, Brasil, n.66, p.77-94, out.- dez. 2017.

GALLO; S.; ASPIS, R. L. Biopolítica-vírus e educação-governamentalidade e escapar e... Revista de Estudos Universitários, Sorocaba, v.37, n.2, p.167-179, dez. 2011.

IMAGINE. Intérprete: John Lennon. Compositores: J. Lennon e Y. Ono. In: Imagine. Nova York: Maclen Music, 1971. LP, faixa 1.

INSTITUTO BRASILEIRO DE GEOGRAFIA E ESTATÍ́STICA - IBGE. Diretoria de pesquisas, coordenação de trabalho e rendimento, pesquisa nacional por amostra de domicílios contínua 2016. Disponível em:

https://biblioteca.ibge.gov.br/visualizacao/livros/liv101631_informativo.pdf. Acesso em: 05 jul. 2018.

INSTITUTO BRASILEIRO DE GEOGRAFIA E ESTATÍ́STICA - IBGE. Diretoria de pesquisas, coordenação de trabalho e rendimento, pesquisa nacional por amostra de domicílios contínua 2018. Disponível em:

https://biblioteca.ibge.gov.br/visualizacao/livros/liv101631_informativo.pdf. Acesso em: 22 dez. 2018

KIRKPATRICK, D. O efeito Facebook: os bastidores da história da empresa que conecta o mundo. Rio de Janeiro: Intrínseca, 2011.

PALFREY, J.; GASSER, U. Nascidos na era digital: entendendo a primeira geração de nativ@s digitais. Porto Alegre: Artmed, 2011.

PRENSKY, M. Digital natives, digital immigrants. On the Horizon, MCB University Press, v.9, n.5, Out. p.1-6, 2001.

RECUERO, R. Redes sociais na internet. Porto Alegre: Sulina, 2009.

REVEL, J. Foucault - conceitos essenciais. São Carlos: Claraluz, 2005.

SCRIMIM, N. D. A influência das mídias sociais na constituição d@s sujeit@s contemporâne@s. 2019. 127f. Dissertação (Mestrado em Educação) - Faculdade de Educação da Universidade Estadual de Campinas, Campinas, 2019. 
SCRIMIM, N.; FRANÇA, L. Vigiar e curtir: uma análise foucaultiana das redes sociais na sociedade do espetáculo. In: 1을 ENCONTRO INTERNACIONAL DE ESTUDOS FOUCAULTIANOS: governamentalidade e segurança, 1., 2014, Anais [...]. p.754-762, Paraíba, 2014.

VEEN, W.; VRAKKING, B. Homo zappiens: educando na era digital. Trad. V. Figueira. Porto Alegre: Artmed, 2009.

VERMELHO, S. C.; VELHO, A. P.M.; BERTONCELLO, V. Sobre o conceito de redes sociais e seus pesquisadores. Educ. Pesqui., São Paulo, Ahead of print, abr. v. 41, n. 4. p.863-881, 2015.

ZUCKERBERG, M. Building global community. Facebook, 2017. Disponível em: https://www.facebook.com/notes/mark-zuckerberg/building-globalcommunity/10154544292806634. Acesso em: Acesso em: 28 de julho de 2018.

ZUCKERBERG, M. Facebook, 2018. Disponível em:

https://www.facebook.com/zuck/posts/10104380170714571. Acesso em: Acesso em: 28 de julho de 2018.

Recebido em março de 2019.

Aprovado em abril de 2019. 